\title{
Obesity in International Migrant Populations
}

\author{
Marie Murphy $^{1} \cdot$ Wendy Robertson ${ }^{1} \cdot$ Oyinlola Oyebode $^{1}$
}

Published online: 28 July 2017

(C) The Author(s) 2017. This article is an open access publication

\begin{abstract}
Purpose of Review This review examines the risk of obesity in migrant groups - specifically migrants from countries with lower prevalence of obesity to countries with higher prevalence of obesity. We examine obesity prevalence within migrant groups compared with native populations and the evidence on factors that might shape obesity risk in these migrant groups.

Recent Findings Migrants may arrive in new countries with a health advantage including generally a healthier body weight. Genetic and epi-genetic factors, as well as body size preference, socio-economic factors, and stress exposure, may play a role in increasing unhealthy weight gain in migrant populations. This unhealthy weight gain leads to similar or greater obesity risk in migrant populations compared with native populations $10-15$ years after migration.

Summary Meeting the challenge of prevention and treatment of obesity in diverse populations will require greater attention to minority groups in research in the future.
\end{abstract}

Keywords Obesity $\cdot$ Migration $\cdot$ Ethnicity $\cdot$ Epidemiology

This article is part of the Topical Collection on The Obesity Epidemic: Causes and Consequences

Oyinlola Oyebode o.r.o.oyebode@warwick.ac.uk

1 Warwick Medical School, University of Warwick, Gibbet Hill Campus, Coventry CV4 7AL, UK

\section{Introduction}

In 2010, overweight and obesity were estimated to have caused 3.4 million deaths and 94 million disability-adjusted life-years worldwide [1]. Worldwide, prevalence of obesity is rising: a systematic analysis for the Global Burden of Disease study examining data on prevalence of overweight and obesity in children and adults from 1980 to 2013 found that overweight and obesity (based on a body mass index (BMI) over $25 \mathrm{~kg} / \mathrm{m}^{2}$ ) had risen by $27.5 \%$ for adults and $47.1 \%$ for children - that is, an increase from 921 million individuals in 1980 to 2.1 billion in 2013 [2•]. While this trend is monotonic in populations across the world, the prevalence and risk of obesity vary between and within populations [2•]. It is likely that the variation in prevalence and risk of obesity is due to genetic (including ethnic) differences between populations as well as due to the variation in the degree to which local environments are 'obesogenic'.

This review examines the risk of obesity in migrant groups, focusing on international migration which is often from regions with low prevalence of obesity to regions with higher prevalence of obesity. In this review, we include 'immigrant' populations within our examination of migrants i.e. those who are settled in their new country, and we will also consider subsequent generations whose parents or grandparents were migrants, wherever possible considering these subsequent generations as distinct groups. Examination of this topic will often involve referring to ethnic groups - groups of people with shared ancestry. We note that any research or discussion of 'the migrant population' will involve some generalisations, and that the migrant population is not homogenous and neither are the many ethnic groups that are often classified based on convenience (e.g. for the sake of sample size, amalgamating people from diverse backgrounds, traditions and cultures as 'black', 'white' and 'Asian'). 
Many differences between the health of migrant and nonmigrant populations have been identified (better and worse), some of which arise from inequalities [3•]. In Europe, in general, migrants are reported to be more vulnerable to communicable diseases, occupational hazards and poor mental health, as well as diabetes and perinatal morbidity [4]. In the USA, migrants live 3.4 years longer than the US-born population, and an advantage in life expectancy remains when stratified by ethnic group [5]. Migrants to the USA are less likely to have a disability, but are more likely to be diagnosed with HIV, have low levels of health insurance coverage and have reduced access to preventative health services [5].

Migration itself is an important determinant of health - due to the economic, physical and mental burden of uprooting and travelling to start life somewhere new [3•]. There are certainly many other factors that might shape obesity risk associated with migration status including intrinsic factors related to the genetic background of individuals, lifestyle factors related to culture and the wider determinants of health including education, occupation and more. Indeed, it is also likely that obesity risk changes with time of residence in the host country. We examine obesity prevalence within migrant groups compared with native populations, and the evidence on factors that might shape obesity risk in these migrant groups.

\section{Obesity Prevalence}

There are two key reasons why we might expect obesity prevalence to be lower in migrants than in native populations [6]. Firstly, migration is stressful and expensive, it can include passing rigorous health checks and, as recently as 50 years ago, long journeys could be physically demanding. For these reasons, migrants (individuals with the capacity to overcome these challenges) are usually healthier than both the population they leave behind and the one they join (the "healthy migrant effect'), with the exception of asylum seekers [3•]. Secondly, destination countries are often those that have reached the stage in the nutrition transition in which there has been increasing fat, sugar and processed food consumption, while source countries are often earlier in this transition. This means that even if migrants were randomly selected from source populations, rather than a healthier self-selecting group, they would be likely to have a lower BMI on arrival than the native population (although note that obesity is increasing worldwide and in some middle-income countries it is particularly high e.g. Mexico).

Consistent with the hypothesis above, there is evidence that newly arrived migrants have a greater prevalence of healthy weight, than native populations. A cross-sectional study of over 250,000 people from the six largest Asian ethnic groups resident in the USA found that after adjustment for age and ethnicity, US-born men had $4 \times$ the odds of being obese than migrant men, and for women the odds were $3.5 \times$ [7]. Similar studies of other migrant populations have reported similar findings [8-11].

Despite this initial advantage, unhealthy weight gain by migrants generally increases substantially so that $10-15$ years post migration, overweight and obesity rates approach or overtake those of the native population $[6,12]$. There has been debate about cohort effects confounding this relationship. This was addressed in a study of six year-of-entry cohorts of immigrants to the USA, which demonstrated that while self-rated health actually improved with a longer duration of residence after accounting for cohort effects, obesity prevalence showed the opposite pattern [13].

The pattern for children is likely to be similar, with slimmer newly arrived migrants, and later unhealthy weight gain. An analysis of the US National Health and Nutrition Examination Survey (NHANES) 1999-2012 found that obesity prevalence was significantly higher in US-born children/adolescents than in those who had been in the USA for under a year; however, this gap decreased from 1999 to 2011 due to a rapid increase in obesity prevalence among the non-US-born population [14]. A systematic review of prevalence of overweight and obesity among European child populations reported that migrant children are at higher risk for overweight and obesity than children from native populations [15]. However, most included studies reported differences by ethnic group, or classified children according to their mother tongue, or parent's country of birth so this is likely to have captured more individuals from subsequent generations than it did true migrant children themselves. Another study suggests that some children of migrants gain weight faster than those with USborn parents [16].

We have discussed why migrant populations are likely to arrive with lower average prevalence of overweight and obesity than resident populations in high-income countries (HICs); however, a number of factors might combine to make weight gain likely in migrant populations after arrival in a new country and in subsequent generations. These will be discussed in turn below, and see Table 1 .

\section{Genetic and Physiological Factors}

Animal and family studies have demonstrated that some of the variation in body composition is likely to have a genetic component [17]. Several hormones are involved in signalling satiety and promoting appetite including leptin, adiponectin and insulin, and production of these molecules is under genetic control. About 127 sites in the human genome have been reported to link with development of obesity [18].

Given that ethnic groups share common ancestry and therefore have genetic similarities, it is possible that there are some ethnic groups that are more prone to development of obesity than others. There are some general differences in physiology between groups defined by ethnicity, which could be under 
Table 1 Factors associated with risk of unhealthy weight gain in migrant populations

\begin{tabular}{|c|c|}
\hline Factor & Conclusion \\
\hline Genetic and physiological factors & $\begin{array}{l}\text { Likely that some genetic differences underlie vulnerability } \\
\text { of different ethnic groups to obesity. No candidate genes yet identified. }\end{array}$ \\
\hline Epi-genetic factors & $\begin{array}{l}\text { Likely that migrant populations are more often predisposed to } \\
\text { increasing obesity risk when exposed to an obesogenic environment. }\end{array}$ \\
\hline Dietary behaviour & $\begin{array}{l}\text { Although migrants may have an increasingly unhealthy diet after } \\
\text { settling in a HIC, their diet is generally healthier than native } \\
\text { populations so this is unlikely to be a major contributor to } \\
\text { increased obesity risk. }\end{array}$ \\
\hline Physical activity & $\begin{array}{l}\text { Migrants generally do more occupational physical activity and } \\
\text { physical activity for travel, but face barriers to engaging in } \\
\text { leisure-time physical activity. Reduced leisure-time physical activity } \\
\text { may become an increasingly important determinant of increased } \\
\text { obesity risk in the future. }\end{array}$ \\
\hline Body size preference & $\begin{array}{l}\text { Preference or tolerance of larger female body sizes is changing } \\
\text { worldwide. This may currently increase obesity risk through } \\
\text { reduced motivation to maintain or lose weight in some migrant groups. }\end{array}$ \\
\hline Acculturation & $\begin{array}{l}\text { In general migrants who maintain their original culture have reduced } \\
\text { obesity risk. }\end{array}$ \\
\hline Socio-economic status & $\begin{array}{l}\text { It is likely that social and economic disadvantage increase obesity } \\
\text { risk in migrants, as with other population groups in HICs. }\end{array}$ \\
\hline Stress & It is plausible that stress experienced by migrants increases obesity risk. \\
\hline
\end{tabular}

genetic control. For example, a study examining healthy lean South Asian and white adults in the Netherlands found that South Asian adults have lower resting energy expenditure, non-shivering thermogenesis and brown adipose tissue volumes which might underlie high susceptibility to obesity and metabolic disorders [19]. In a study of Asian Indian, Creole and white Swedish men and women, Asian Indians of both sexes and Creole men had higher leptin levels than white Swedish men and women [20].

Some historical migrant populations may have been shaped by exposure to particularly challenging journeys. This may have applied a selective pressure to the populations in which only those individuals capable of surviving tough conditions completed the journey to pass on genetic material to subsequent generations. The example of Africans who travelled to the USA during the slave trade is an extreme example of this.

Researchers have examined whether genetic differences might underlie differing vulnerability to obesity and metabolic disorders between ethnic groups e.g. [21]. However, despite this being theoretically possible, to our knowledge, genes that might be responsible have not been identified.

\section{Epi-genetic Factors}

Sometimes known as the 'Barker Hypothesis' (after the proponent of the theory) or the 'Thrifty phenotype', the idea that susceptibility to adult disease can be programmed in the womb has been supported by human and animal studies [22, 23]. According to this theory, an adverse environment in the prenatal and perinatal period can programme the foetus to have a particular metabolic profile in later life. Specifically poor maternal nutrition can programme the foetus to be more likely to store calories as fat, and have elevated fasting blood sugar. While this may have been evolutionarily advantageous, because the individual is metabolically prepared for an environment in which food is scarce, in the case that there is under-nutrition in the womb and then later exposure to a calorie-rich, fat-rich, sugar-rich diet, this backfires and the individual becomes vulnerable to obesity and other adult diseases. The percentage of babies born with a low birth weight (one marker of insufficient nutrition in the womb) is particularly high in low- and middle-income countries (LMICs) at $27 \%$ of live births [24]. This has been postulated as the cause of increased overweight and obesity in international adoptees living with Swedish families in Sweden [25] and for the differences between Britishborn and migrant UK Pakistani women in a very small study that found British-born women were taller and had healthier metabolic markers than the Pakistani-born women [26]. In a sample of 337 sub-Saharan African children who had migrated to Australia, higher prevalence of overweight and obesity was associated with lower birth weight [27]. It is clear that migrants from LMICs to HICs may be more likely to have had poor nutrition prenatally or in early life, which may then predispose these individuals to obesity when in the HIC's obesogenic context. 


\section{Cultural Factors}

\section{Dietary Behaviour}

Dietary behaviour varies widely among and within different cultures. When people migrate, dietary practices are often disrupted, so that different types of food are consumed or preparation of food is modified [28]. Of course, migrants also frequently influence the tastes of native populations, increasing the range of foods on offer in host countries.

A systematic mapping of 37 primary studies examining dietary behaviour in minority ethnic groups across Europe found that factors influencing dietary behaviour included cultural identity, religious beliefs and prescribing, and taste preferences [29•]. Specific factors influencing dietary behaviour identified for migrant populations were availability of traditional foods (noting that when these are imported they can be more expensive), competency in new language and perception of host culture (including eating behaviours and food habits) [29•].

A review of dietary habits of minority ethnic groups in Europe reports that the majority of migrants combine part of their traditional diet with some of the less healthy elements of the European diet [28]. Usually, the staple foods remain (such as rice, breads, noodles) while more processed foods are consumed in addition, particularly by younger generations (such as breakfast cereal, soft drinks and high-fat high-sugar snacks) [28]. A survey of 599 Mexican-origin women found that US-born, Mexicanorigin women consumed more sugar-sweetened beverages and more fast-food meals than Mexican-born, Mexicanorigin women [30]. As well as increasing consumption of unhealthy foods associated with the diet of the new country, there is a theory that foods traditionally eaten at festivals (which have a higher calorie, sugar and fat content than other traditional foods) which would have been eaten a few times a year on special occasions become part of the new daily diet of settled migrants, with supporting data from the USA and UK [31]. In addition, a qualitative research study with 25 Pakistan-born women living in Oslo, Norway, revealed an increasing social pressure to be a good host with an expectation of serving an abundance of different dishes to honour guests [32].

Despite the increased consumption of unhealthy items in migrants who settle in a new country, evidence from both the USA and UK suggests that dietary practices are still generally healthier in migrant than native populations. For example, analysis of NHANES data 2007-2008 demonstrated that US households with a foreign-born reference person cooked more dinners at home (mean of 5.8 per week) than households with a US-born reference person (mean of 4.9 per week) which is usually a marker of better diet quality [33]. Mexican Americans born in Mexico have higher consumption of fruit and vegetables, and a higher overall percentage of energy coming from healthy food sources than non-Hispanic White Americans or Mexican Americans born in the USA [34].

In the UK, large health survey data suggests that minority ethnic groups have some elements of a healthier diet than the white British population including a larger proportion who meet the recommended five portions of fruit and vegetables a day, particularly within Chinese and African-Caribbean groups, and generally lower fat intakes [35]. Breast-feeding rates are also higher for minority ethnic groups [35], and there is lower alcohol consumption in Asian, black Caribbean and black African ethnic groups living in the UK [36].

There are exceptions to the generally healthier diet. One example from the USA is that Mexican-born women (nonpregnant, aged 15-44 years) have lower serum folate compared with US-born Mexican women regardless of supplement use [37]. In the UK, those from minority ethnic groups report using more salt [35]. Migrant groups in the Netherlands are less likely to have breakfast than Dutchborn groups [38]. However, given that overall, there is some evidence that diet in migrant groups is healthier than that of native populations, it is unlikely that diet alone is responsible for the increasing risk of obesity in settled migrant populations.

\section{Physical Activity}

Age-standardised prevalence of insufficient physical activity in adults aged $15+$ years presented by the WHO, based on data from 2008, showed the highest rates of physical inactivity in high-income countries, with upper middle-income countries very close behind and lower rates of inactivity in lower middle- and low-income countries [39]. In terms of the WHO region, the Americas and Eastern Mediterranean regions had the highest rates of inactivity (approaching 50\% of women and $40 \%$ of men). The lowest rates on inactivity were seen in the African (approximately $30 \%$ of women and $25 \%$ of men) and South-East Asian regions (approximately $20 \%$ for women, $15 \%$ for men) [39]. This suggests that migrants from LMIC to HIC will be moving from more physically active populations to less physically active populations, in general.

Analysis of objectively measured physical activity data from NHANES showed that there were significant differences in the amount of moderate to vigorous physical activity achieved by different population groups delineated by ethnicity and migrant status in the USA. Migrant white and Hispanic groups and the female migrant-black group achieved more physical activity than their US-born counterparts, but for male black groups, this was reversed [10]. Another NHANES study showed that US-born Mexican Americans engaged in more minutes per week of leisure time physical activity relative to Mexican-born counterparts. However, US-born individuals 
were also more likely to report having done no work or travelrelated physical activity and therefore reported fewer minutes of total physical activity [40]. For children, analysis of the US National Survey of Children's Health showed that migrant children were substantially less likely than native-born children to engage in sports and physical activity [5] which was reflected in analysis of the Canadian Health Behaviour in School-Aged Children Study [41].

There are a number of barriers to participation in leisure time physical activity experienced by migrant groups. One of the main barriers reported in the literature is a restriction on opportunity for women to take part in physical activity primarily due to religious dress codes. In societies set up to cater for this, there may be women-only settings in which women are able to exercise - but on migration to a new society, these opportunities are reduced. In the UK, the gap between male and female participation in sport is greater among minority ethnic groups than in the population as a whole [42].

Other barriers to participation in sport in UK minority ethnic groups, including migrant groups, are overt racism (e.g. name-calling), cultural factors (e.g. less acceptable for children to go to a park without their parents) and factors which may be related to socio-economic status, which will be discussed in more detail below (e.g. fear of attacks or mugging and poor access to or condition of leisure facilities) [42]. In a study of Somali women living in Sweden, climate was also considered a barrier to an active lifestyle [43].

It seems likely that migrants generally do more occupational physical activity and physical activity for travel and less leisure time physical activity than native populations. This may change as fewer jobs require physical activity [44], and it seems likely that motorisation of transport will continue. In this scenario, leisure time physical activity may become a more important determinant of rates of obesity in migrant groups.

\section{Body Size Preference}

There has been much research examining whether different cultures have a different preference in terms of body size, particularly of women. Where food is scarce, higher body fat may be seen as a sign of high status, and considered preferable for survival and reproduction [23]. It is difficult to determine which population groups value larger body sizes - for example black women in the USA tend to be heavier than their white counterparts and express less dissatisfaction with their weight; however, this may be due to higher overall self-esteem among black women [45]. A study of more than 1200 men and women living in the USA found that ethnicity had no influence on preference for female or male shapes or tolerance for obesity [45]. In a questionnaire study, the majority of Black Somali mothers living in the UK felt that being overweight in childhood can be healthy, which was considerably higher than parents from other ethnic backgrounds; however, a similar pattern was not observed in the broader 'Black African' group in this sample [46]. A systematic review of beauty ideals and body dissatisfaction in Africans living in Africa and Europe found that ethnic groups living in greater isolation or with low incomes prefer a larger body shape, but that those in urban areas and in Europe have increasing BMI and body dissatisfaction [47]. A qualitative study of Moroccan-born women in the Netherlands and in Morocco found that all participants reported their preferences shifting to slimmer body sizes but that weight gain was still seen as a sign of success [48]. It is likely that migrant groups from LMICs in general have a preference or a tolerance of larger female body sizes than HIC populations, which might influence desire to maintain or lose weight. However, this may well be changing.

\section{Acculturation}

Migrants are immersed in their host environment and undergo acculturation to some degree, i.e. changing attitudes and behaviour under the influence of the host culture. A systematic review of evidence on the relationship between acculturation and overweight/obesity among adult migrants from LMICs to HICs identified nine studies and reported that for men, acculturation promotes unhealthy weight gain, but for women there were inconsistent results [12]. This suggests that in general, migrants who maintain attitudes and behaviour associated with the country of origin are protected from the increasing obesity risk. In this review, the authors hypothesise that for some women, the adverse dietary and physical activity changes associated with the new environment are off-set by the social norms in many HICs which value slim female bodies. This hypothesis is supported by one of the included studies in which obese Mexican Americans with low levels of acculturation were more satisfied with their weight and body shape than those who were highly acculturated [12].

\section{Wider Determinants of Health}

\section{Socio-economic Status}

It is well documented that there is a link between better socioeconomic status and better health [49]. Systematic reviews report that for adults and children in HICs, the least disadvantaged groups are less likely to be obese while in low-income countries there is a positive relationship between socioeconomic status and obesity, which reverses with increasing economic development [50-53]. There are likely to be many mediators of the relationship between socio-economic status and obesity including knowledge of the aetiology of disease and causes of obesity, as well as barriers associated with money, time and opportunities (e.g. within a local neighbourhood) to eat a healthy diet or take part in physical activity. 
Migrants tend to settle in areas with cheap housing and are more likely to hold jobs which are less prestigious, to have poorer job security and to endure more stressful working conditions including working unsociable hours [54]. Subsequent generations generally demonstrate significant upward social mobility, although some groups experience marginalisation and reduced opportunities [55]. Even when migrant groups have similar current incomes, there can be large differences in education levels, material resources (e.g. property ownership) and accumulated wealth [56].

Although many studies examine the contribution of socioeconomic status to differences in obesity by ethnic group, very few consider migration status. In terms of ethnicity, studies have reported that deprivation does affect the engagement of minority ethnic groups in physical activity [42], but differences in children's obesogenic lifestyles between ethnic groups in the UK were not explained by deprivation [57]. Where migration status is examined, results are mixed. For example, in a study examining changes in waist circumference over time in Chinese and Hispanic immigrants to the USA, there was some evidence that living in neighbourhoods more supportive of healthy behaviour (specifically walkability and recreational resources both of which are associated with more expensive neighbourhoods) tempered the increases in waist circumference in the Chinese group, but not the Hispanic group [58]. The lack of findings on socio-economic status and unhealthy weight gain in migrant populations does not mean this is not an important mediator; it is more likely challenges in measuring socio-economic status (particularly in migrants) which makes this difficult to study.

\section{Stress}

Migration may be associated with a lack of social support in the new country, social isolation (due to language, cultural or administrative barriers) and sometimes experiences of marginalisation or racism. These factors mean that some migrants are likely to experience some degree of stress. Stress has been linked to obesity [59, 60], for example through an association between stress and increased food intake, as well as potentially physiological effects of stress on metabolism [61, 62].

A meta-analysis of 293 studies found that experience of racism is significantly related to poorer health [63]. When obesity-related outcomes including BMI, waist circumference and waist-to-hip ratio were examined specifically, these were also significantly associated with racism. A third of included studies examined migrant populations, although the majority were conducted with native-born populations in the USA [63]. A systematic review identified 32 studies that found racism had a negative impact on the involvement and experiences of minority ethnic groups in sport in the UK at both elite and grassroots level and both men and women's sports [42].
Although racism is part of the additional stress on migrants, it seems likely that other components (such as social isolation) would be greater in migrants than in other minority ethnic groups. To examine the effect that stress has on the body, some researchers use 'allostatic load' which is a physiological measure of the cumulative impact of stress on the body derived through a combination of blood pressure measurements, pulse rate and inflammatory markers in the blood. In a study of allostatic load in US-born and migrant black adults, migrants were found to have reduced allostatic load compared with the US-born [64]. In conclusion, stress as a mediator of unhealthy weight gain in migrant groups is a plausible theory, but without much current evidence.

\section{Addressing Obesity in Migrant Groups}

\section{Thresholds for Action}

Adult obesity is a risk factor for type 2 diabetes, cardiovascular disease, cancer, osteoarthritis, chronic kidney disease, lateonset Alzheimer's disease and pregnancy complications [65-67]. It is associated with reduced life expectancy and reduced healthy life expectancy. Child obesity is a risk factor for adult obesity and associated health consequences [68], but is also independently associated with premature mortality, early-onset type 2 diabetes, asthma, musculoskeletal problems, psychological problems and cardiovascular risk factors including hypertension and hypercholesterolaemia [69].

It is highly likely that the same degree of obesity poses a greater health risk for certain ethnic groups; however, determining this empirically is complex. Firstly, common measurements of obesity (such as BMI) may reflect differing accumulations of body fat and in general these may over- or under-predict true obesity [70]. Secondly, even with equal amounts of body fat, where this is distributed and given that abdominal obesity gives rise to greater health risks than subcutaneous obesity, this may result in differing risk. Both these things are likely to be heritable and could vary between ethnic groups [71]. There are even more complications when considering thresholds for childhood obesity, given the influence of different ages of growth and sexual maturation on body composition, which can vary by ethnic group [72-74]. Lastly, even with equal amounts and distribution of body fat, the health consequences of obesity may differ between groups because of underlying differences in physiology (e.g. variations in the blood-circulatory system), culture (e.g. age at which people start a family) and environment (e.g. health care access).

Fifteen years ago, a WHO expert consultation examined whether adult Asian populations have different associations between BMI, percentage body fat and health risks than do European populations [75]. This was done to determine 
recommended BMI thresholds for overweight and obesity in Asian populations. The WHO consultation concluded that there was wide variation among Asian populations and that the international cutoff points for BMI categories should be retained. However, they also recommended additional, lower trigger points for Public Health action in Asian populations (Table 2). In the UK, in 2013, the National Institute for Health and Care Excellence (NICE) went further by extending the recommended lower thresholds to black African and African-Caribbean populations in the UK [76].

Both sets of recommendations were based on patchy evidence of mixed quality. In particular, the main outcomes considered were type 2 diabetes and cardiovascular disease, and categorisation of ethnic groups was broad. Very little evidence exists on the other health risks associated with obesity, and homogenising ethnic groups may hide important differences between distinct populations. In fact, in a study published since the NICE guidance examining half a million UK Biobank participants, South Asian and Chinese groups were demonstrated to have a similar risk of type 2 diabetes at very different BMI (22 vs $24 \mathrm{~kg} / \mathrm{m}^{2}$ ) and waist circumference (79 vs $88 \mathrm{~cm}$ ), which suggests the amalgamation of these groups in the NICE and WHO guidance as 'Asian' may not be appropriate [70]. In addition, the evidence presented at NICE was conflicting on whether lower or higher thresholds were appropriate for black populations, despite the decision to then recommend a lower threshold for individuals within these groups.

Other attempts at quantifying risk based on obesity and ethnicity include a joint scientific statement from a number of US and international bodies, which proposes a definition of metabolic syndrome based on differing thresholds for waist circumference in different populations, some of which correspond to ethnic groups [77]. There have been no attempts to officially recommended thresholds for identifying overweight and obesity in children specific to ethnic background, although unofficial thresholds have been proposed [74].

It is highly likely that different ethnic groups have different levels of health risk, in general, at the same BMI and even at the same percentage body fat, but existing evidence does not adequately quantify this. Best practice is likely to involve using indicators of obesity in the context of other personal information on risk factors when considering clinical action.

\section{Specific Interventions}

Obesity prevention and treatment interventions are recommended in clinical guidance worldwide e.g. [78, 79]. In terms of migrant populations, a key issue is that there may be a difference in intervention effectiveness in some populations, but there is a lack of representation in studies. For example, a Cochrane review of childhood obesity interventions noted that the majority of research in the field had been conducted with 'motivated, middle-class, Caucasian populations' which means it may not be generalizable to other populations groups [80]. Similarly, a systematic review of health promotion interventions for minority ethnic groups found that there is currently a lack of evidence on how best to delivery physical activity or healthy eating interventions in these populations [81]. A recent systematic review of interventions to prevent obesity in US migrant populations identified 20 studies [82•]. Although the majority of the included studies were quasiexperimental and therefore limited in terms of the conclusions that can be drawn, the interventions which showed positive effects on obesity all incorporated some cultural focus [82•].

More recently, in the UK, a culturally appropriate intervention for prevention of childhood obesity in the South Asian population was promising in a feasibility study [83] and is now being examined in a definitive cluster randomised controlled trial [84]. A further obesity treatment intervention for Pakistani and Bangladeshi children is also underway [85].

Taken together, the evidence suggests that culturally adapted obesity interventions can be effective-perhaps through increasing the salience, acceptability and uptake of these interventions by migrant groups. However, the number of obesity prevention and treatment interventions for migrant populations does not reflect the growing and diverse groups of immigrants in HICs, and more evidence-based culturally relevant interventions are needed.

\section{Methods}

We searched MEDLINE and Google scholar in May 2017 to identify relevant literature. This was supplemented with reference searching and the authors' personal libraries of relevant literature. We aimed to examine relevant systematic
Table 2 International guidance on BMI thresholds for adult Asian populations

\begin{tabular}{lll}
\hline White European populations & Asian populations & Description \\
\hline Less than $18.5 \mathrm{~kg} / \mathrm{m}^{2}$ & Less than $18.5 \mathrm{~kg} / \mathrm{m}^{2}$ & Underweight \\
$18.5-24.9 \mathrm{~kg} / \mathrm{m}^{2}$ & $18.5-23 \mathrm{~kg} / \mathrm{m}^{2}$ & Increasing but acceptable risk \\
$25-29.9 \mathrm{~kg} / \mathrm{m}^{2}$ & $23-27.5 \mathrm{~kg} / \mathrm{m}^{2}$ & Increased risk \\
$30 \mathrm{~kg} / \mathrm{m}^{2}$ or higher & $27.5 \mathrm{~kg} / \mathrm{m}^{2}$ or higher & High risk \\
\hline
\end{tabular}

Source: WHO 2004 [69], NICE 2013 [80] 
reviews from the past 10 years, as well as key studies on predetermined topics from the last 3-5 years in order to complete this narrative review. These topics were based on an agreed framework for the review and included epidemiology of obesity, factors contributing to obesity prevalence and addressing obesity in migrant groups.

\section{Limitations in the Evidence Base}

Being repeated throughout our review, we note a general lack of evidence on migrant or generation status in research on ethnic differences in health and the determinants of health. Where it is considered, amalgamations make it difficult to tease apart effects for distinct migrant groups. Also, this topic is complex and it is difficult to account for the roles of length of time in new country vs cohort effects; specific country of origin; the intersection of religion, ethnicity and migrant status; socio-economic status in country of origin, etc. Patterns of health across migrant groups are likely to be dynamic, not stable, for example depending on factors relating to the social, economic and political environment in home and new country at the time of migration and changes in these environments over time, particularly relating to the nutrition transition. This means that findings from one setting may not be generalizable to others.

\section{Conclusion}

Between 1990 and 2015, the number of international migrants worldwide rose by over 91 million or by $60 \%$ [86]. Migrants may arrive in new countries with a health advantage including generally a healthier body weight; however, intrinsic and environmental factors combine to cause unhealthy weight gain, often to beyond the levels seen in native populations. Meeting the challenge of prevention and treatment of obesity in diverse populations will require greater attention to minority groups in research in the future.

\section{Compliance with Ethical Standards}

Conflict of Interest Marie Murphy, Wendy Robertson, and Oyinlola Oyebode declare they have no conflict of interest.

Human and Animal Rights and Informed Consent This article does not contain any studies with human or animal subjects performed by any of the authors.

Open Access This article is distributed under the terms of the Creative Commons Attribution 4.0 International License (http:// creativecommons.org/licenses/by/4.0/), which permits unrestricted use, distribution, and reproduction in any medium, provided you give appropriate credit to the original author(s) and the source, provide a link to the Creative Commons license, and indicate if changes were made.

\section{References}

Papers of particular interest, published recently, have been highlighted as:

- Of importance

1. Lim SS, Vos T, Flaxman AD, Danaei G, Shibuya K, Adair-Rohani H, et al. A comparative risk assessment of burden of disease and injury attributable to 67 risk factors and risk factor clusters in 21 regions, 1990-2010: a systematic analysis for the Global Burden of Disease Study 2010. Lancet (London, England). 2012;380(9859):2224-60.

2. Ng M, Fleming T, Robinson M, Thomson B, Graetz N, Margono C, et al. Global, regional, and national prevalence of overweight and obesity in children and adults during 1980-2013: a systematic analysis for the Global Burden of Disease Study 2013. Lancet (London, England). 2014;384(9945):766-81. This paper indicates obesity prevalence worldwide which can be useful for considering the situation in 'source' countries.

3. Bhopal RS. Migration, ethnicity, race, and health in multicultural societies. 2nd ed. Oxford: Oxford University Press; 2014.

Excellent overview of the complex interplay between migration, ethnicity and race and how these act as determinants of health.

4. Rechel B, Mladovsky P, Ingleby D, Mackenbach JP, McKee M. Migration and health in an increasingly diverse Europe. Lancet (London, England). 2013;381(9873):1235-45.

5. Singh GK, Rodriguez-Lainz A, Kogan MD. Immigrant health inequalities in the United States: use of eight major national data systems. Sci World J. 2013;2013. Available from: http://view. ncbi.nlm.nih.gov/pubmed/24288488.

6. Hao L, Kim JJ. Immigration and the American obesity epidemic. Int Migr Rev. 2009;43(2):237-62.

7. Lauderdale DS, Rathouz PJ. Body mass index in a US national sample of Asian Americans: effects of nativity, years since immigration and socioeconomic status. Int J Obes Relat Metab Disord. 2000;24(9):1188-94.

8. Cairney J, Ostbye T. Time since immigration and excess body weight. Can J Public Health = Revue canadienne de sante publique. 1999;90(2):120-4.

9. Albrecht SS, Diez Roux AV, Aiello AE, Schulz AJ, Abraido-Lanza AF. Secular trends in the association between nativity/length of US residence with body mass index and waist circumference among Mexican-Americans, 1988-2008. Int J Public Health. 2013;58(4): 573-81.

10. Wen M, Kowaleski-Jones L, Fan JX. Ethnic-immigrant disparities in total and abdominal obesity in the US. Am J Health Behav. 2013;37(6):807-18.

11. Mehta NK, Elo IT, Ford ND, Siegel KR. Obesity among U.S.- and foreign-born blacks by region of birth. Am J Prev Med. 2015;49(2): 269-73.

12. Delavari M, Sønderlund ALL, Swinburn B, Mellor D, Renzaho A. Acculturation and obesity among migrant populations in high income countries - a systematic review. BMC Public Health. 2013;13(1):458+.

13. Ro A, Geronimus A, Bound J, Griffith D, Gee G. Cohort and duration patterns among Asian immigrants: comparing trends in obesity and self-rated health. Biodemography Soc Biol. 2015;61(1):65-80.

14. Tsujimoto T, Kajio H, Sugiyama T. Obesity, diabetes, and length of time in the United States: analysis of National Health and Nutrition Examination Survey 1999 to 2012. Medicine. 2016;95(35):e4578.

15. Labree LJ, van de Mheen H, Rutten FF, Foets M. Differences in overweight and obesity among children from migrant and native origin: a systematic review of the European literature. Obes Rev. 2011;12(5):e535-47. 
16. Van Hook J, Baker E. Big boys and little girls: gender, acculturation, and weight among young children of immigrants. J Health Soc Behav. 2010;51(2):200-14.

17. Willyard C. Heritability: the family roots of obesity. Nature. 2014;508(7496):S58-60.

18. Singh RKK, Kumar P, Mahalingam K. Molecular genetics of human obesity: a comprehensive review. C R Biol. 2017;340(2):87-108.

19. Bakker LE, Boon MR, van der Linden RA, Arias-Bouda LPP, van Klinken JB, Smit F, et al. Brown adipose tissue volume in healthy lean south Asian adults compared with white Caucasians: a prospective, case-controlled observational study. Lancet Diabetes Endocrinol. 2014;2(3):210-7.

20. Lilja M, Rolandsson O, Shaw JE, Pauvaday V, Cameron AJ, Tuomilehto J, et al. Higher leptin levels in Asian Indians than Creoles and Europids: a potential explanation for increased metabolic risk. Int J Obes (2005). 2010;34(5):878-85.

21. Sohani ZN, Deng WQ, Pare G, Meyre D, Gerstein HC, Anand SS. Does genetic heterogeneity account for the divergent risk of type 2 diabetes in South Asian and white European populations? Diabetologia. 2014;57(11):2270-81.

22. Barker DJ, Winter PD, Osmond C, Margetts B, Simmonds SJ. Weight in infancy and death from ischaemic heart disease. Lancet. 1989;2(8663):577-80.

23. Wells JC. Thrift: a guide to thrifty genes, thrifty phenotypes and thrifty norms. Int J Obes (2005). 2009;33(12):1331-8.

24. Lee AC, Katz J, Blencowe H, Cousens S, Kozuki N, Vogel $\mathrm{JP}$, et al. National and regional estimates of term and preterm babies born small for gestational age in 138 lowincome and middle-income countries in 2010. Lancet Glob Health. 2013;1(1):e26-36.

25. Johansson-Kark M, Rasmussen F, Hjern A. Overweight among international adoptees in Sweden: a population-based study. Acta Paediatr (Oslo, Norway: 1992). 2002;91(7):827-32.

26. Pollard TM, Unwin N, Fischbacher C, Chamley JK. Differences in body composition and cardiovascular and type 2 diabetes risk factors between migrant and British-born British Pakistani women. Am J Hum Biol. 2008;20(5):545-9.

27. Renzaho AM, Gibbons C, Swinburn B, Jolley D, Burns C. Obesity and undernutrition in sub-Saharan African immigrant and refugee children in Victoria, Australia. Asia Pac J Clin Nutr. 2006;15(4): 482-90.

28. Gilbert PA, Khokhar S. Changing dietary habits of ethnic groups in Europe and implications for health. Nutr Rev. 2008;66(4):203-15.

29. Osei-Kwasi HAA, Nicolaou M, Powell K, Terragni L, Maes L, Stronks K, et al. Systematic mapping review of the factors influencing dietary behaviour in ethnic minority groups living in Europe: a DEDIPAC study. Int J Behav Nutr Phys Act. 2016;13:85. Sixtythree factors influencing dietary behaviour in minority ethnic groups are put into seven clusters.

30. Sharkey JR, Johnson CM, Dean WR. Nativity is associated with sugar-sweetened beverage and fast-food meal consumption among Mexican-origin women in Texas border colonias. Nutr J. 2011;10:101.

31. Azar KMJ, Chen E, Holland AT, Palaniappan LP. Festival foods in the immigrant diet. J Immigr Minor Health. 2013;15(5):953-60.

32. Mellin-Olsen T, Wandel M. Changes in food habits among Pakistani immigrant women in Oslo, Norway. Ethn Health. 2005;10(4):311-39.

33. Virudachalam S, Long JA, Harhay MO, Polsky DE, Feudtner C. Prevalence and patterns of cooking dinner at home in the USA: National Health and Nutrition Examination Survey (NHANES) 2007-2008. Public Health Nutr. 2014;17(5):1022-30.
34. Batis C, Hernandez-Barrera L, Barquera S, Rivera JA, Popkin BM. Food acculturation drives dietary differences among Mexicans, Mexican Americans, and non-Hispanic whites. J Nutr. 2011;141(10):1898-906.

35. Leung G, Stanner S. Diets of minority ethnic groups in the UK: influence on chronic disease risk and implications for prevention. Nutr Bull. 2011;36(2):161-98.

36. Rao R, Schofield P, Ashworth M. Alcohol use, socioeconomic deprivation and ethnicity in older people. BMJ Open. 2015;5(8): e007525.

37. Marchetta CM, Hamner HC. Blood folate concentrations among women of childbearing age by race/ethnicity and acculturation, NHANES 2001-2010. Matern Child Nutr. 2016;12(1):39-50.

38. Reijneveld SA, van Nieuwenhuijzen M, Klein Velderman M, Paulussen TW, Junger M. Clustering of health and risk behaviour in immigrant and indigenous Dutch residents aged 19-40 years. Int J Public Health. 2012;57(2):351-61.

39. World Health Organisation. Chapter 1: burden: mortality, morbidity and risk factors. The Global Status report on noncommunicable diseases 2010. April 2011. Accessed $26^{\text {th }}$ June 2017. http://www. who.int/nmh/publications/ncd report chapter1.pdf?ua=1.

40. Murillo R, Albrecht SS, Daviglus ML, Kershaw KN. The role of physical activity and sedentary behaviors in explaining the association between acculturation and obesity among Mexican-American adults. Am J Health Promot. 2015;30(1):50-7.

41. Kukaswadia A, Pickett W, Janssen I. Time since immigration and ethnicity as predictors of physical activity among Canadian youth: a cross-sectional study. PLoS One. 2014;9(2):e89509.

42. Long J, Hylton K, Spracklen K, Ratna A, Bailey S. Systematic review of the literature on black and minority ethnic communities in sport and physical recreation. Leeds: Carnegie Research Institute; 2009.

43. Persson G, Mahmud AJJ, Hansson EEE, Strandberg ELL. Somali women's view of physical activity-a focus group study. BMC Womens Health. 2014;14:129.

44. Church TS, Thomas DM, Tudor-Locke C, Katzmarzyk PT, Earnest CP, Rodarte RQ, et al. Trends over 5 decades in U.S. occupationrelated physical activity and their associations with obesity. PLoS One. 2011;6(5):e19657+

45. Cachelin FM, Rebeck RM, Chung GH, Pelayo E. Does ethnicity influence body-size preference? A comparison of body image and body size. Obes Res. 2002;10(3):158-66.

46. Trigwell J, Watson P, Murphy R, Stratton G, Cable N. Ethnic differences in parental attitudes and beliefs about being overweight in childhood. Health Educ J. 2014;73(2):179-91.

47. Toselli S, Rinaldo N, Gualdi-Russo E. Body image perception of African immigrants in Europe. Glob Health. 2016;12(1):48.

48. Nicolaou M, Benjelloun S, Stronks K, van Dam RM, Seidell JC, Doak CM. Influences on body weight of female Moroccan migrants in the Netherlands: a qualitative study. Health Place. 2012;18(4): 883-91.

49. Marmot MG. Understanding social inequalities in health. Perspect Biol Med. 2003;46(3 Suppl):S9-23.

50. Kinge JMM, Strand BHH, Vollset SEE, Skirbekk V. Educational inequalities in obesity and gross domestic product: evidence from 70 countries. J Epidemiol Community Health. 2015;69(12):1141-6.

51. Dinsa GD, Goryakin Y, Fumagalli E, Suhrcke M. Obesity and socioeconomic status in developing countries: a systematic review. Obes Rev. 2012;13(11):1067-79.

52. Pampel FC, Denney JT, Krueger PM. Obesity, SES, and economic development: a test of the reversal hypothesis. Soc Sci Med (1982). 2012;74(7):1073-81. 
53. Barriuso L, Miqueleiz E, Albaladejo R, Villanueva R, Santos JM, Regidor E. Socioeconomic position and childhood-adolescent weight status in rich countries: a systematic review, 1990-2013. BMC Pediatr. 2015;15:129.

54. Nazroo JY. Genetic, cultural or socio-economic vulnerability? Explaining ethnic inequalities in health. Sociol Health Illn. 1998;20(5):710-30.

55. Park J, Myers D. Intergenerational mobility in the post-1965 immigration era: estimates by an immigrant generation cohort method. Demography. 2010;47(2):369-92.

56. Braveman PA, Cubbin C, Egerter S, Chideya S, Marchi KS, Metzler M, et al. Socioeconomic status in health research: one size does not fit all. JAMA. 2005;294(22):2879-88.

57. Falconer CL, Park MH, Croker H, Kessel AS, Saxena S, Viner RM, et al. Can the relationship between ethnicity and obesityrelated behaviours among school-aged children be explained by deprivation? A cross-sectional study. BMJ Open. 2014;4(1):e003949.

58. Albrecht SS, Osypuk TL, Kandula NR, Gallo LC, Lê-Scherban F, Shrager S, et al. Change in waist circumference with longer time in the United States among Hispanic and Chinese immigrants: the modifying role of the neighborhood built environment. Ann Epidemiol. 2015;25(10):767.

59. Wilson SM, Sato AF. Stress and paediatric obesity: what we know and where to go. Stress Health. 2014;30(2):91-102.

60. Block JP, He Y, Zaslavsky AM, Ding L, Ayanian JZ. Psychosocial stress and change in weight among US adults. Am J Epidemiol. 2009;170(2):181-92.

61. Morris MJ, Beilharz JE, Maniam J, Reichelt AC, Westbrook RF. Why is obesity such a problem in the 21 st century? The intersection of palatable food, cues and reward pathways, stress, and cognition. Neurosci Biobehav Rev. 2015;58:36-45.

62. Sinha R, Jastreboff AM. Stress as a common risk factor for obesity and addiction. Biol Psychiatry. 2013;73(9):827-35.

63. Paradies Y, Ben J, Denson N, Elias A, Priest N, Pieterse A, et al. Racism as a determinant of health: a systematic review and metaanalysis. PLoS One. 2015;10(9):e0138511.

64. Doamekpor LA, Dinwiddie GY. Allostatic load in foreign-born and US-born blacks: evidence from the 2001-2010 National Health and Nutrition Examination Survey. Am J Public Health. 2015;105(3): 591-7.

65. Dixon JB. The effect of obesity on health outcomes. Mol Cell Endocrinol. 2010;316(2):104-8.

66. Prospective Studies Collaboration. Body-mass index and causespecific mortality in 900,000 adults: collaborative analyses of 57 prospective studies. Lancet. 2009;373:1083-96.

67. Marchi J, Berg M, Dencker A, Olander EK, Begley C. Risks associated with obesity in pregnancy, for the mother and baby: a systematic review of reviews. Obes Rev. 2015;16:621-38. doi:10.1111/obr.12288.

68. Simmonds M, Llewellyn A, Owen CG, Woolacott N. Predicting adult obesity from childhood obesity: a systematic review and meta-analysis. Obes Rev. 2016;17:95-107. doi:10.1111/obr.12334.

69. Conolly A, Children's BMI. Overweight and obesity. In: Craig R, Mindell J, editors. Health survey for England 2015. Leeds: Health and Social Care Information Centre; 2016.

70. Sweeting HN. Measurement and definitions of obesity in childhood and adolescence: a field guide for the uninitiated. Nutr J. 2007;6:32+.

71. Nazare JAA, Smith JD, Borel ALL, Haffner SM, Balkau B, Ross R, et al. Ethnic influences on the relations between abdominal subcutaneous and visceral adiposity, liver fat, and cardiometabolic risk profile: the International Study of Prediction of Intra-Abdominal Adiposity and Its Relationship With Cardiometabolic Risk/Intra-Abdominal Adiposity. Am J Clin Nutr. 2012;96(4):714-26.
72. Shaw NJ, Crabtree NJ, Kibirige MS, Fordham JN. Ethnic and gender differences in body fat in British schoolchildren as measured by DXA. Arch Dis Child. 2007;92(10):872-5.

73. Ridler C, Townsend N, Dinsdale H, Mulhall C, Rutter H. National Child Measurement Programme: detailed analysis of the 2007/08 National Dataset. Oxford: National Obesity Observatory; 2009.

74. Hudda MT, Nightingale CM, Donin AS, Fewtrell MS, Haroun D, Lum S, et al. Body mass index adjustments to increase the validity of body fatness assessment in UK black African and South Asian children. Int J Obes. 2017;41(7):1048-55.

75. WHO Expert Consultation. Appropriate body-mass index for Asian populations and its implications for policy and intervention strategies. Lancet (London, England). 2004;363(9403):157-63.

76. National Institute of Health and Care Excellence. BMI: preventing ill health and premature death in black, Asian and other minority ethnic groups. Public health guidelines [PH46]. July 2013.Ntuk UE, Gill JM, Mackay DF, Sattar N, Pell JP. Ethnic-specific obesity cutoffs for diabetes risk: cross-sectional study of 490,288 UK biobank participants. Diabetes Care. 2014;37(9):2500-7.

77. Alberti KG, Eckel RH, Grundy SM, Zimmet PZ, Cleeman JI, Donato KA, et al. Harmonizing the metabolic syndrome: a joint interim statement of the International Diabetes Federation Task Force on Epidemiology and Prevention; National Heart, Lung, and Blood Institute; American Heart Association; World Heart Federation; International Atherosclerosis Society; and International Association for the Study of Obesity. Circulation. 2009;120(16):1640-5.

78. National Institute of Health and Care Excellence. Obesity. Identification, assessment and management. NICE guidelines [CG 189]. November 2014.

79. National Institutes of Health. National Heart, Lung and Blood Institute. Clinical guidelines on the identification, evaluation and treatment of overweight and obesity in adults. NIH Publication no. 98-4083. 1998.

80. Oude Luttikhuis H, Baur L, Jansen H, Shrewsbury VA, O'Malley C, Stolk RP, et al. Interventions for treating obesity in children. Cochrane Database Syst Rev. 2009;21(1):CD001872.

81. Liu J, Davidson E, Bhopal R, White M, Johnson M, Netto G, et al. Adapting health promotion interventions to meet the needs of ethnic minority groups: mixed-methods evidence synthesis. Health Technol Assess. 2012;16(44):1-469.

82. Tovar A, Renzaho AM, Guerrero AD, Mena N, Ayala GX. A systematic review of obesity prevention intervention studies among immigrant populations in the US. Curr Obes Rep. 2014;3:206-22. Reviews 20 studies focused on obesity interventions for immigration populations in the USA.

83. Adab P, Pallan MJ, Cade J, Ekelund U, Barrett T, Daley A, et al. Preventing childhood obesity, phase II feasibility study focusing on South Asians: BEACHeS. BMJ Open. 2014;4:e004579.

84. Adab P, Pallan MJ, Lancashire ER, et al. A cluster-randomised controlled trial to assess the effectiveness and costeffectiveness of a childhood obesity prevention programme delivered through schools, targeting 6-7 year old children: the WAVES study protocol. BMC Public Health. 2015;15: 488. doi:10.1186/s12889-015-1800-8.

85. Pallan M, Griffin T, Lancashire E, Hurley K, Blissett J, Frew E, et al. Cultural adaptation of a children's weight management programme for Bangladeshi and Pakistani families in the UK: a clusterrandomised feasibility study protocol. Pilot Feasibility Stud. 2016;2:48.

86. United Nations Department of Economic and Social Affairs/ Population Division. International Migration Report 2015. Accessed $5^{\text {th }}$ June 107: http://www.un.org/en/development/desa/ population/migration/publications/migrationreport/docs/ MigrationReport2015.pdf. 